\title{
Description of the adult and immature stages of Clunio ponticus Michailova, 1980 (Diptera, Chironomidae), from the Black Sea, VARNA, BULgaria
}

\author{
Joel Moubayed $^{1 *}$, Paraskeva Michailova ${ }^{2}$ and Peter H. Langton ${ }^{3}$ \\ ${ }^{1}$ Freshwater \& Marine biology, 10 rue des Fenouils, F-34070 Montpellier, France. \\ E-mail: joelmb34@free.fr, corresponding author \\ ${ }_{2}^{2}$ Institute of Biodiversity and Ecosystem research, Bulgarian Academy of Sciences, Tzar Osvoboditel 1, \\ Sofia 1000.E-mail:pmichailova@yahoo.com \\ ${ }^{3}$ University Museum of Zoology Cambridge, Downing Street, Cambridge, UK CB2 3EJ. (Address for cor- \\ respondence: 16 Irish Society Court, Coleraine, Co. Derry, BT52 IGX, Northern Ireland). \\ E-mail: langtonph@gmail.com
}

\begin{abstract}
The mature and immature stages of Clunio ponticus Michailova, 1980 are diagnosed and described based on associated material recently collected in the marine littoral zone of Varna, St-Konstantin and Helena Resorts, Black Sea (eastern Bulgaria). Male and female adults, pupae and larvae of $C$. ponticus can be easily distinguished from other known European Clunio species on the basis of some atypical features found in the male and female adults, pupal exuviae and fourth instar larvae. In addition, the biological cycle (reproduction and emergence) of $C$. ponticus is not synchronized with lunar periodicity (new and full moon) as for some other known Clunio species from Europe, but closely related to the typology of the intertidal zone along the coastline of the Black Sea. This indicates that this species is a local biogeographic representative of the 'Pontus Region', which includes the eastern coastline of the Black Sea. Remarks on related known Clunio species from Europe with comments on the ecology and geographical distribution of $C$. ponticus are given.
\end{abstract}

\section{Introduction}

Data on the taxonomy and geographical distribution of known marine species belonging to the genus Clunio Haliday, 1855 (Strenzke 1960; Olander \& Palmén 1968; Neumann 1976; Sæther 1977; Heimbach 1978; Michailova 1980a, 1980b; Coffman et al. 1986; Cranston et al. 1989; Langton 1991; Neumann et al. 1997; Langton \& Pinder 2007; Tasdemir 2010; Ashe \& O’Connor 2012; Kaiser \& Heckel 2012; Sæther \& Spies 2013; Moubayed-Breil \& Ashe 2012; Andersen et al. 2013; Moubayed-Breil et al. 2013; MoubayedBreil \& Ashe 2016; Abdelsalam, 2017) show that there are currently five known valid species from the sea coasts of Europe and neighbouring areas: C. balticus Heimbach, 1978; C. boudouresquei
Moubayed-Breil, 2019; C. marinus Haliday, 1855; C. mediterraneus Neumann, 1966 and C. ponticus Michailova, 1980. For C. ponticus the larva was described based on the species-specific cytogenetic characteristics and SEM analysis of some male characters (Michailova 1980a, 1980b).

In this paper, $C$. ponticus is diagnosed and described as male and female adults, pupal exuviae and larvae based on recent investigations conducted by P. Michailova in the Black Sea at Varna seashore (eastern Bulgaria). Based on some atypical characters found in the male adult (frontal area of head, palpomeres, ridge of tergites VIII, apodemes of hypopygium, gonostylus), female adult (palp, apodemes of gonapophysis VIII), pupal exuviae (absence of hook rows on sternites) and larva (median tooth of mentum widely domed), this species appears to belong to a local marine biogeographic representative of the 'Pontus Region', which includes the eastern coastline of the Black Sea.

Larval stages of $C$. ponticus are marine dwellers of the intertidal zone along the seacoast of Varna, where various types of perturbation and degradation of the marine habitats have been observed over the last four decades. The type locality where larvae and pupae were collected consists of rocky shores with a dense population of Cladophora algae.

The $C$. ponticus community at the Varna locality is perceived to be a potential environmental indicator of the Varna seashore, where changes in ecological conditions of the intertidal zone presumably are the results of human activities and global warming.

\section{Material and methods}

Material composed of adults, pupae and larvae of C. ponticus was collected using standard methods: troubleau net (mesh $500 \mu \mathrm{m})$ for the benthos (lar- 
vae and pupae) and individuals floating on the surface of the water; sweep net for flying adults. The examined material of male and female adults was preserved in $96 \%$ ethanol, then cleared of musculature in $90 \%$ lactic acid (head, thorax, abdomen and anal segment) for 60 to 80 minutes but this can be left overnight at room temperature without any detrimental effect or damage. The specimens were checked under a binocular microscope after 20 minutes in lactic acid to determine how the clearing was progressing. When clearing was complete the specimens were washed in two changes of 50 to $60 \%$ ethanol to ensure that all traces of lactic acid were removed. The specimens were then mounted in polyvinyl lactophenol. Before the final slide mounting, the hypopygium including tergites VIII- IX and anal point, the gonocoxite and the gonostylus, were viewed ventrally and laterally to examine and draw from both sides all the necessary details. The ventral view of hypopygium was illustrated with the anal point and tergite IX omitted. The abdominal segments I-VII of the male adult was preserved in $85 \%$ ethanol for an eventual DNA analysis.

Morphological terminology and measurements follow those of Sæther (1980), Langton (1991) and Langton \& Pinder (2007) for the imagines, pupal exuviae and larvae. Taxonomic remarks on some related known species from Europe with comments on the ecology of $C$. ponticus are given.

\section{Description}

\section{Clunio ponticus Michailova, 1980}

Holotype and paratypes in Institute of Biodiversity and Ecosystem research, Bulgarian Academy of Sciences, Sofia, Bulgaria (Michailova 1980b).

\section{Material examined}

Topotypes: 30 male adults, 2 female adults, 2 pharate females, 1 male pupal exuviae, 7 larva, Varna, Bulgaria. rocky seashores at Varna beach, St. Konstantin and Helena Resorts (4313'45' N and $28^{\circ} 0{ }^{\prime} 30^{\prime \prime}$ E) (locus typicus), 26.VI.2019, leg. P. Michailova. Water temperature: low $10-12{ }^{\circ} \mathrm{C}$; high $22-25{ }^{\circ} \mathrm{C}$.

Material is deposited in the authors' collections as follows: 5 male adults (JM); 23 male adults including 7 mounted on slides and 14 preserved in ethanol 95\%, 2 female adults, 7 larvae (PM); 1 male adult, 2 pharate females, 1 male pupal exuviae (PHL). 1 male adult mounted on 1 slide is deposited in the Zoologische Staatssammlung München (ZSM), Germany.

\section{Diagnostic characters}

Although $C$. ponticus is keyed near $C$. mediterraneus and $C$. boudouresquei, some atypical morphological characters found in male and female adults and pupal exuviae enable us to separate this species from its congeners. The species is also distinguished by its ecology and the stability of its biological cycle, which is not related to the lunar periodicity as for most populations of $C$. marinus, C. mediterraneus and C. boudouresquei. The following combination of morphological characters will separate $C$. ponticus from other related species:

Male adult: frontal margin of head atypically straight and not projecting. Antenna 10-segmented; pedicels conical, closely inserted at their base on midline of head; segment 1 globular with 1 long seta; segment 2 linearly elongated and swollen proximally and distally, bearing 2 long setae on distal half and 5-6 shorter setae apically; last flagellomere as long as the 3 preceding segments, slightly bent apically; AR 0.40-0.43. Palp 2-segmented, palpomere 2 sub-circular with 2 long setae ( 1 dorsal and 1 ventral), inner apical margin pointed. Ridge of tergite VIII long, drop-shaped with 8 median setae (4 on each side of the midline). Hypopygium. Inferior volsella wider at base, narrowing distally and ending with parallel-sided margins; basal apodeme umbrella-shaped, caudal apodeme with 3 long, thin, spine-like extensions, anterior one distinctly curved downwards. Gonostylus with basal tooth crochet-shaped and conspicuous, posterior area with 4 pointed and characteristic teeth; crista dorsalis a wide lobe, long extended and occupying about $90 \%$ of the anterior side; megaseta absent.

Female adult: antenna 7-segmented. Segment 3 as long as the 2 preceding segments, last flagellomere slightly longer than the 3 preceding segments, AR about 0.45 ; apical segment of palp sub-circular, bearing 2 long setae ( 1 dorsal, 1 ventral) and several shorter setae located close to the margin; tergite VIII with a large drop-like posterior margin; gonocoxite elongated vertically and weakly prominent; tergite IX ellipsoidal to egg-shaped; gonapophysis VIII, dorsomesal lobe convex medially, apodeme lobe swollen medially and thicker distally, seminal sac ovoid; cercus bean-shaped with 2 long dorsal setae located on 1 side.

Pupal exuviae: anterior transverse rows of points present on tergite II-VII, not broken medially on any tergite; posterior transverse rows of hooks present on sternites III-VII; posterior transverse rows of hooks absent on sternites. 
Fourth instar larvae: clypeus trapezoidal; setae 1 and 2 plumose, occasionally with branches; setae 3 and 4 are simple. Antenna 5-segmented; ring organ located close to pedestal; segment 2 with a lancetshaped style reaching apex of segment 4; segments 3 and 4 sub-equal. Median tooth of mentum widely domed, and smooth. Mandible with 5 teeth. Pecten epipharyngis with lanceolate setae on both sides.

\section{Male adult}

$(\mathrm{n}=6$; Figs 1-5)

Clunio sp. 1, Moubayed-Breil \& Dominici (2019)

Total length 2.70-2.90 mm. Wing length 1.35-1.40 $\mathrm{mm}, \mathrm{TL} / \mathrm{WL}=2-2.10$. General colouration contrasting brown to dark brown. Head and antennae dark brown; thorax contrasting light brown to brown with dark brown mesonotal stripes; wing pale translucent; legs brown to dark brown; tergites I-VII brown, tergite VIII and hypopygium distinctly contrasting light brown to dark brown.

Head (Figs 1A, 2A-E). Eyes sub-circular without dorsomedian extension, densely hairy with long and short pin-like microtrichiae; microtrichiae absent from inner lateral eye margin, outer posterior margin lacking setae. Frontal area of head (Figs 1A, 2A, 2D-E) atypically with a straight anterior margin, vertex not projecting; temporals 4 consist of 2 inner and 2 outer verticals, postorbitals absent. Antenna (Figs 1B-C, 2A-C) 10-segmented, about 575-585 $\mu \mathrm{m}$ long, bearing a few short setae located on all segments; pedicels (Fig. 2A) conical (funnel-like) with sclerotized margins, closelyconnected at their base and inserted on the midline of head; segments 1-2 (Figs 1B, 2A-B), respectively 70 and $165-175 \mu \mathrm{m}$ long, segment 1 globular with 1 long seta, segment 2 linearly elongated, swollen in its proximal and distal parts, thinner medially, bearing 2 long setae on distal half and 5-6 shorter setae apically; segments 7-9 globular, nearly sub-equal (20-25 $\mu \mathrm{m}$ long), bearing sensilla chaetica; ultimate flagellomere (Figs 1C, 2B-C) 140-150 $\mu \mathrm{m}$ long, about $35 \mu \mathrm{m}$ maximum width, as long as the 3 preceding segments, thumb-like, bearing 6-7 long setae; antennal groove reaching segment 2; AR 0.40-0.43. Palp (Figs 1D, 2D-E) 2-segmented, lacking sensilla clavata; palpomere 2 similarly shaped, sub-circular, about $30 \mu \mathrm{m}$ long, with 2 long setae (1 dorsal and 1 ventral), inner apical margin projecting and pointed apically. Clypeus semi-circular and bare.

Thorax. Antepronotum well-developed, distinctly domed with joined lobes. Antepronotals absent; acrostichals 2-3 starting close to antepronotum; dorsocentrals 3 in 1 row; prealars absent; scutel- lum with 6 stout setae located 3 on each side of the midline. Wing. Brachiolum with 1 stout seta; number of setae on veins: $\mathrm{R}, 4-5 ; \mathrm{R}_{1} 4-5$ located distally; remaining veins and squama bare. Legs (Figs 3A-D). Femur of PI distinctly broad basally (about 180-85 $\mu \mathrm{m}$ maximum width), femur of PII and PIII are narrower (about 50-55 $\mu \mathrm{m}$ ). Tibial spurs of third leg curved apically (Fig. 3C); length (in $\mu \mathrm{m}$ ) of tibial spurs: PI, 30; PII, 45; PIII, $50 \mu \mathrm{m}$ long. Tarsomeres $\mathrm{ta}_{3}$ and $\mathrm{ta}_{4}$ of PI and PII (35 and $30 \mu \mathrm{m}$ long) shorter than tarsomere $\operatorname{ta}_{5}$ (45 and 60 ), while only tarsomere ta $\mathrm{t}_{4}$ of PIII (45) is shorter than tarsomere $\operatorname{ta}_{5}(70)$. Tarsomere $\mathrm{ta}_{3}$ of third leg is long and thin (Fig. 3C). Value of SV (Table 1) of PII and PIII (8.64 and 10.64) is much higher than in PI (4.67). Sensilla chaetica present on tibia and tarsomere ta ${ }_{1}$ of PI-PIII, those on tibiae are located apically. Length $(\mu \mathrm{m})$ and proportions of legs as in Table 1.

Abdomen and anal segment (Figs 1 E-L, 4A-E). Ridge of tergite VIII (Fig. 1E) 70-75 $\mu \mathrm{m}$ long, broad drop-shaped with a slightly narrowing pointed apex; 8 setae are located medially (4 on each side of the caudal part of ridge). Hypopygium in dorsal and ventral view as in Figs 1F-L and Figs 4B-C; dorsal view (Figs 1F, 4 B), ventral view with tergite IX omitted (Figs 1H-I, 4C). Tergite IX 265-275 $\mu \mathrm{m}$ long, $200 \mu \mathrm{m}$ maximum width at base and 100-120 $\mu \mathrm{m}$ at apex, anal point absent; dorsal side (Figs 1F, 4B) densely covered with macrotrichia-like setae reclinate (orally directed) setae about 35-40 short setae; ventral side (Figs 1H-I) with a semi-circular posterior lamella covered with macrotrichia. Apodemes consist of 4 distinct parts (basal, axial, lateral and caudal): basal apodeme (ba, Figs 1G, 4B-C) about $200 \mu \mathrm{m}$ maximum width, umbrella-shaped with anterior side convex; axial apodeme (aa, Figs 1 G-H, 4BC) about 235-245 $\mu \mathrm{m}$ long, ending with a bi-lobed semi-circular apical expansion; lateral apodeme (la, Figs 1H, 4C) 270-280 $\mu \mathrm{m}$ long, inwardly bent distally to connect with caudal apodeme; caudal apodeme (ca, Figs 1H-I, 4C) on each lateral side with 3 long, pointed, spine-like extensions, basal one claw-like with a downwardly curved apex, the two others are upwardly projecting apically. Gonocoxite (Figs 1F, 4C, 4E) about 420-450 $\mu \mathrm{m}$ long, 160-170 $\mu \mathrm{m}$ maximum width, distal inner area with a dense group of proclinate short setae. Inferior volsella (Figs 1F, 4C) about $70 \mu \mathrm{m}$ long in its median part and about $35 \mu \mathrm{m}$ in its distal half, conical basally and nearly parallel-sided in its distal half, densely covered with short upwardly directed setae. Gonostylus (Figs 1J-L, 4C-E, 5AD) $240-250 \mu \mathrm{m}$ long, inverted triangular, much thinner in median and distal parts, arched with 
rounded posterior angle, antero-lateral end projecting upwards into a pointed anterior apex; basal part with a well-sclerotized tooth, crochet-like and conspicuous, rounded at base and pointed apically; posterior part (Figs 1K-L, 4D, 5C) with 4 pointed teeth (clearly visible when viewed laterally, as in Figs $1 \mathrm{~K}-\mathrm{L}$ ), posterior one is much longer than the 3 others. Crista dorsalis (Figs 2J, 4D, 5C) well-developed, a single wide lobe occupying about $90 \%$ of the anterior side; megaseta absent.

Table 1. Male adult of Clunio ponticus. Length $(\mu \mathrm{m})$ and proportions of fore- (PI), mid- (PII) and hind (PIII) legs.

\begin{tabular}{c|c|c|c|c|c|c|c|c|c|c|c}
\hline & $\mathbf{f e}$ & $\mathbf{t i}$ & $\mathbf{t a}_{\mathbf{1}}$ & $\mathbf{t a}_{\mathbf{2}}$ & $\mathbf{t a}_{\mathbf{3}}$ & $\mathbf{t a}_{\mathbf{4}}$ & $\mathbf{t a}_{\mathbf{5}}$ & $\mathbf{L R}$ & $\mathbf{B V}$ & $\mathbf{S V}$ & $\mathbf{B R}$ \\
\hline PI & 485 & 595 & 125 & 38 & 35 & 30 & 45 & 0.21 & 8.14 & 8.64 & 0.70 \\
PII & 610 & 560 & 110 & 50 & 35 & 35 & 60 & 0.20 & 7.11 & 10.64 & 2.50 \\
PIII & 530 & 520 & 225 & 190 & 122 & 45 & 70 & 0.43 & 2.99 & 4.67 & 1.40 \\
\hline
\end{tabular}

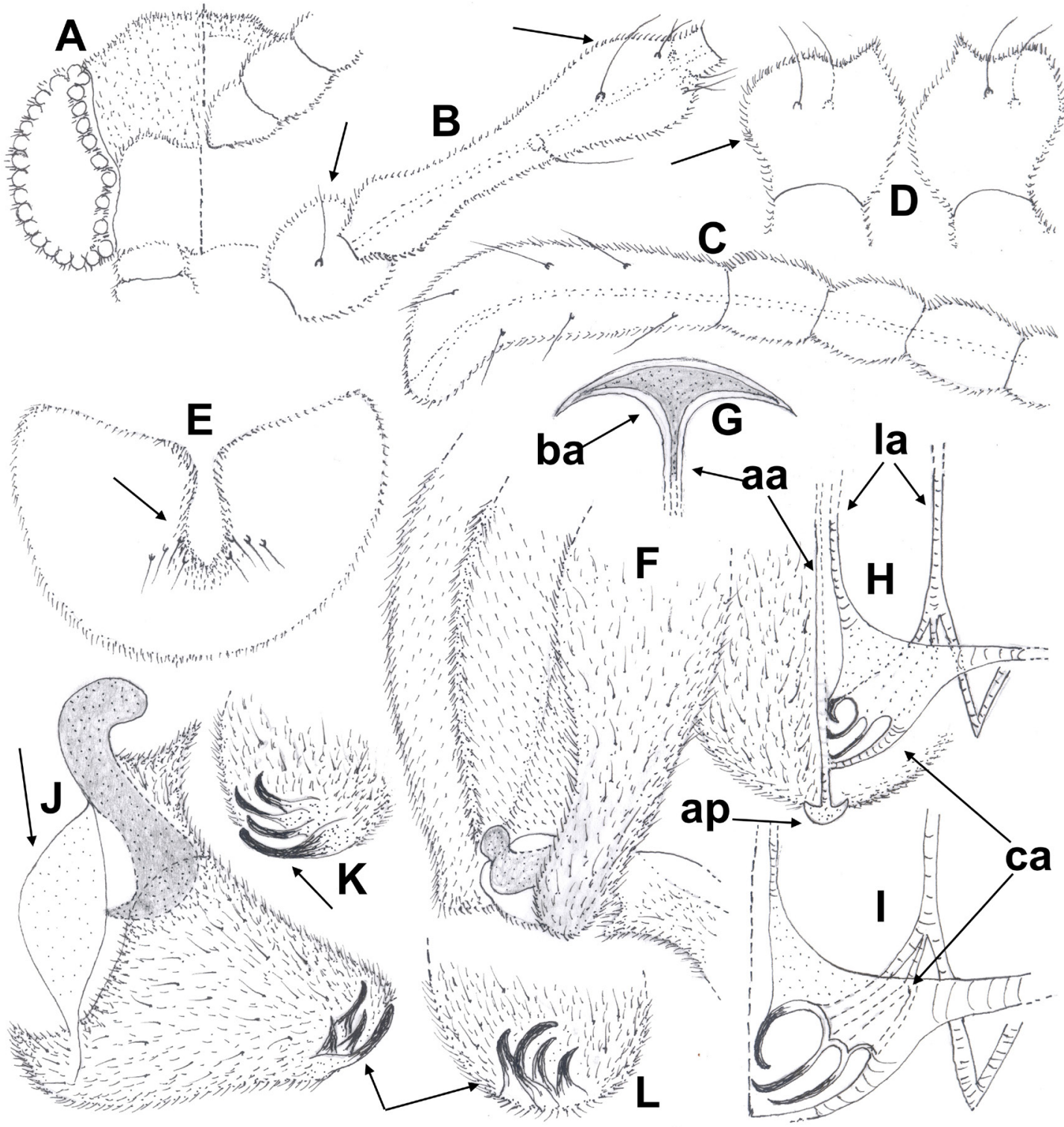

Figure 1. Male adult of Clunio ponticus. A) head in dorsal and ventral view; B) antenna, segments 1-2; C) antenna, segments 7-9 and last flagellomere; D) palp, palpomeres 2 (left and right); E) ridge of tergite VIII; F) hypopygium: gonocoxite, inferior volsella, tergite IX, axial apodeme and apical projection, dorsal view; G) basal and axial sternapodeme, dorsal view; H-I) lateral and caudal apodemes in ventral view; J) gonostylus, dorsal view; K-L) apex of gonostylus, different views. $\mathrm{ba}=$ basal apodeme; $\mathrm{aa}=$ axial apodeme; $\mathrm{la}=$ lateral apodeme; $\mathrm{ca}=$ caudal apodeme. The arrows indicate some distinguishing characters. 


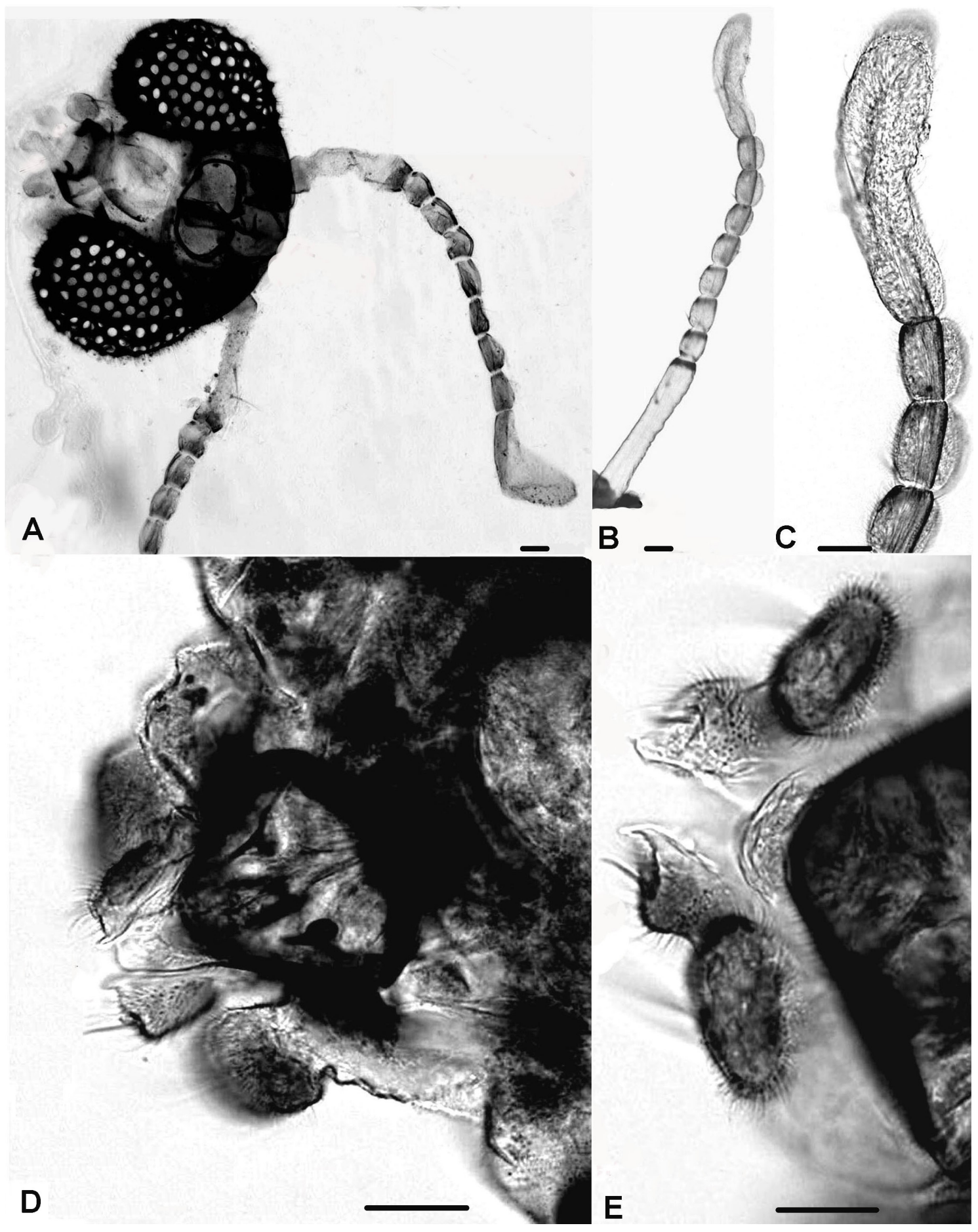

Figure 2. Male adult of Clunio ponticus. A) head (frontal view) and antenna; B) antenna, segments 2-10; C) antenna, segments 7-9 and last flagellomere; D-E) palp, palpomere left and right. Scale bar $=10 \mu \mathrm{m}$. 


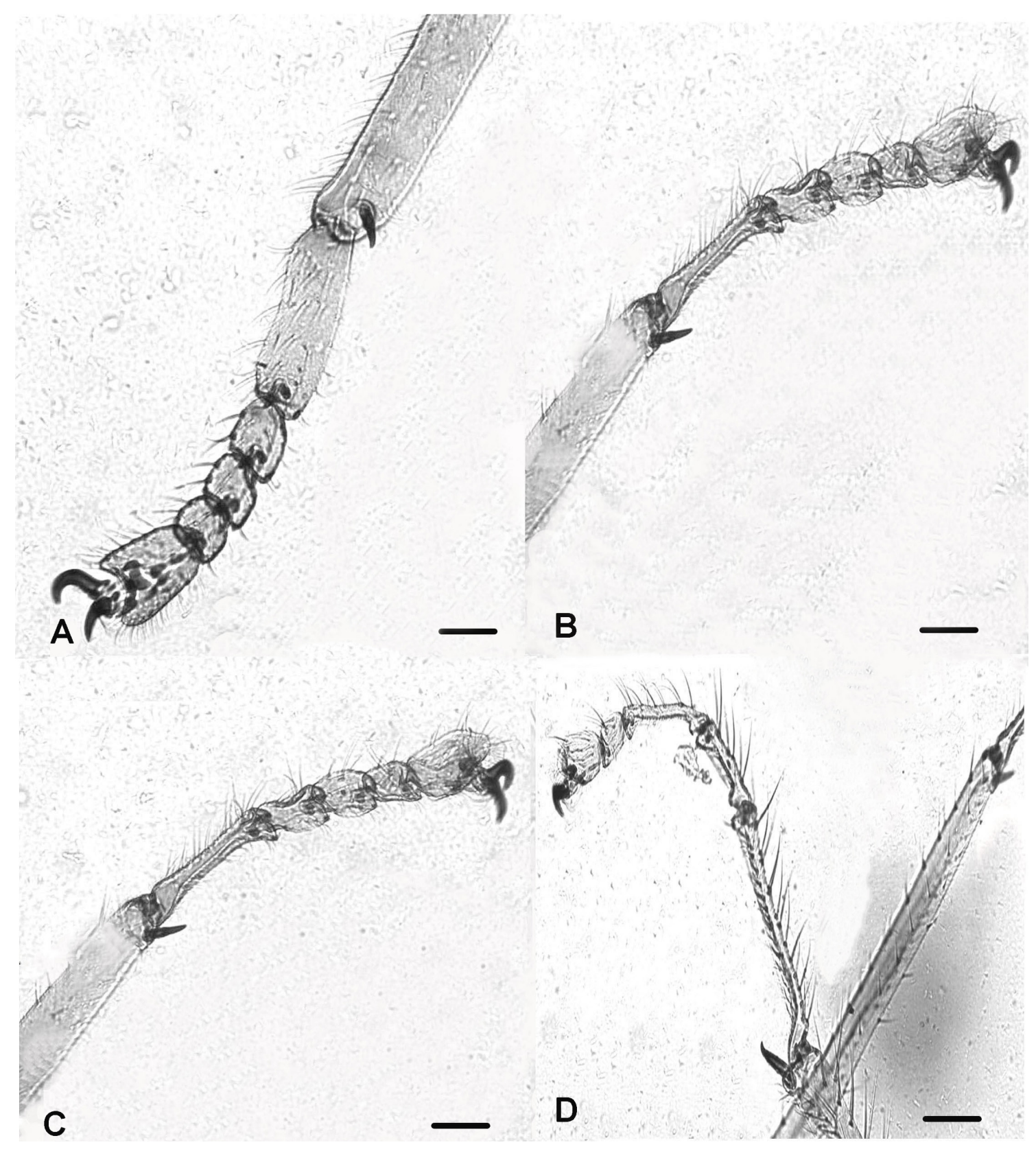

Figure 3. Male adult of Clunio ponticus. Legs, tibial spurs and tarsomeres of fore leg (A), mid leg (B) and hind leg (C-D). Scale bar $=10 \mu \mathrm{m}$. 


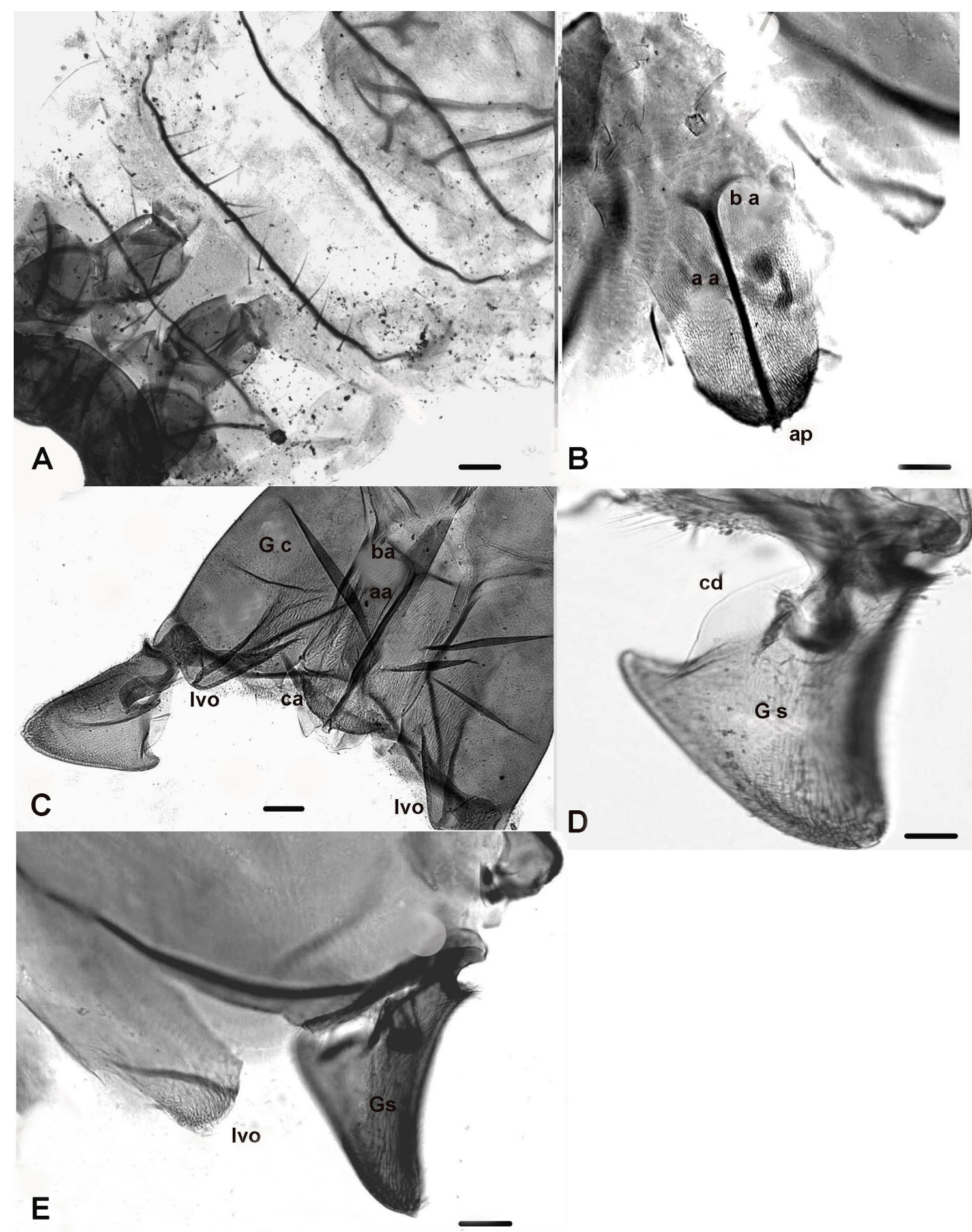

Figure 4. Male adult of Clunio ponticus. A) chaetotaxy of first abdominal segments; B) tergite IX with basal (ba) and axial (aa) apodemes and apical projection (ap); C) hypopygium with gonocoxite (Gc), inferior volsella (Ivo), apodemes and gonostylus (Gs); D) gonostylus with crista dorsalis (cd); E) Inferior volsella and gonostylus. Scale bar $=10 \mu \mathrm{m}$. 

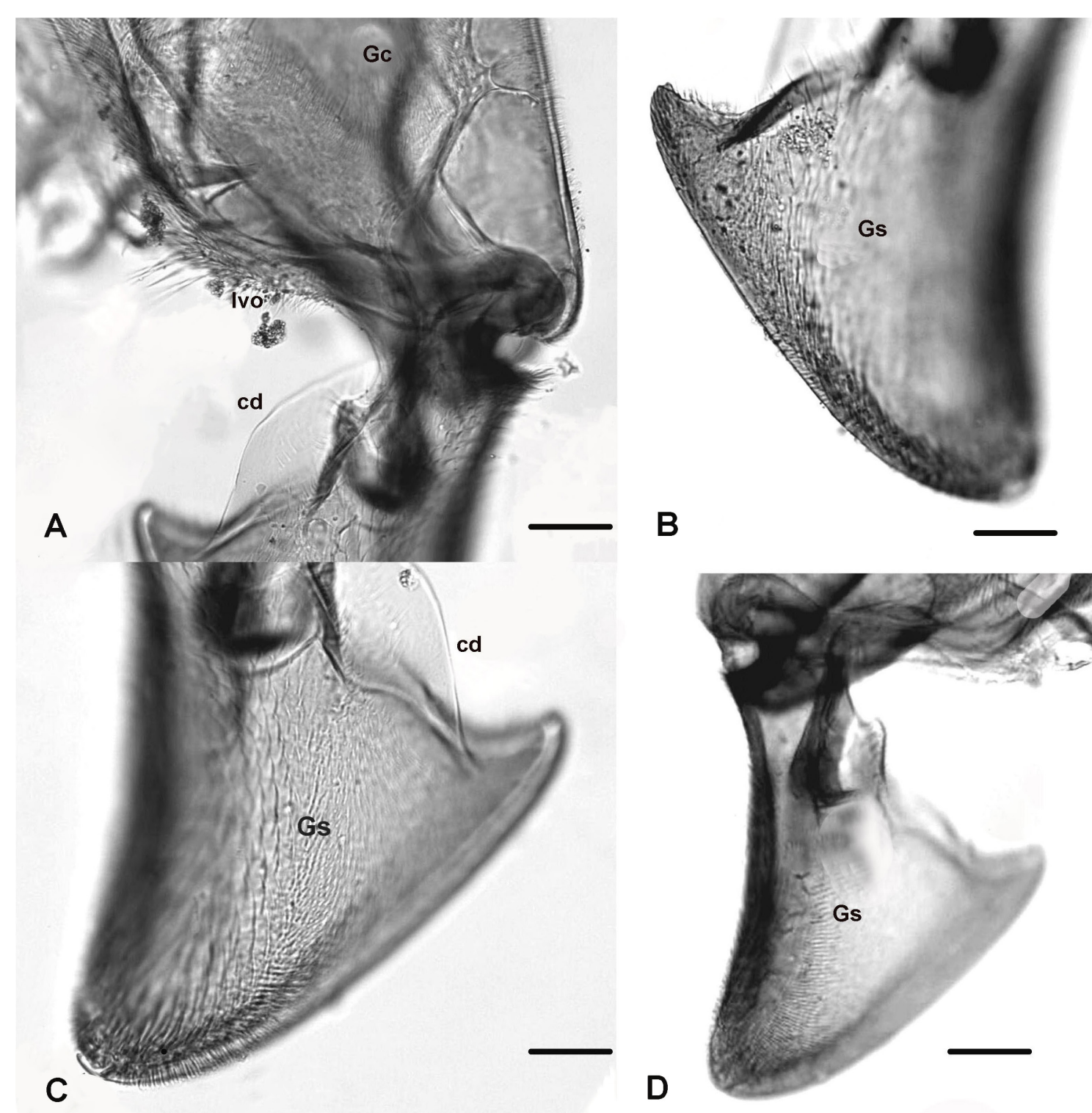

Figure 5. Male adult of Clunio ponticus. A) gonocoxite (Gc), inferior volsella (Ivo) and crista dorsalis (cd); B-D) different aspects of gonostylus. Scale bar $=10 \mu \mathrm{m}$.

\section{Female adult}

$(\mathrm{n}=3$; Figs 6-8)

Small as in all female Clunio species. Total length $1.55-1.65 \mathrm{~mm}$. General colouration less contrasting than in the male adult; head dark brown with light brown antennae; thorax brownish; legs brown with blackish claws; tergites I-VII brownish, tergite VIII and anal segment distinctly contrasting light brown to dark brown.

Head (Figs 6A-B, 7A-B). Eyes densely hairy, subcircular without dorso-median extension, microtrichiae absent from inner and lateral eye margin, outer posterior margin lacking setae. Frontal area straight (Figs 7A-B); temporals 3, including 1 inner and 2 outer verticals. Antenna 7-segmented (Figs 6A; 7C), about 190-200 $\mu \mathrm{m}$ long; last flagellomere 55-60 $\mu \mathrm{m}$ long, swollen proximally and nearly parallel-sided in its distal half; antennal groove reaching segment 2; AR 0.45. Palp (Figs 6B, 7A-B) 2-segmented; segment 1, indistinct; palpomere 2 about $20 \mu \mathrm{m}$ long, sub-circular to globular, bearing 2 long fine setae.

Thorax. Chaetotaxy indistinct and difficult to observe. Legs (Figs 7D-G). Tibia of PII and PIII nearly equal (115 and $118 \mu \mathrm{m}$ long); tarsomeres $\mathrm{ta}_{2}-\mathrm{ta}_{4}$ of PI and PIII equal in size. Femur of PI is much wider $(85 \mu \mathrm{m})$ than in PII-PIII (60 and 55); tibia of PIII is wider $(50 \mu \mathrm{m})$ than in PI and PII (40 $\mu$ m each); tibial spur (Fig. 7F) strongly curved apically. LR value of PIII (0.54) much higher than in PI and PII (0.28 and 0.25); SV value of PII (9.02) much higher than in PIII (4.32). Few sensilla chaetica present on tibia and tarsomere ta $\mathrm{ta}_{1}$ of PI, PII and PIII. Length (in $\mu \mathrm{m}$ ) and proportions of legs as in Table 2. 
Table 2. Female adult of Clunio ponticus. Length $(\mu \mathrm{m})$ and proportions of fore- (PI), mid- (PII) and hind (PIII) legs.

\begin{tabular}{|c|c|c|c|c|c|c|c|c|c|c|c|}
\hline & $\mathbf{f e}$ & $\mathbf{t i}$ & $\mathbf{t a}_{\mathbf{1}}$ & $\mathbf{t a}_{\mathbf{2}}$ & $\mathbf{t a}_{\mathbf{3}}$ & $\mathbf{t a}_{\mathbf{4}}$ & $\mathbf{t a}_{\mathbf{5}}$ & $\mathbf{L R}$ & $\mathbf{B V}$ & $\mathbf{S V}$ & $\mathbf{B R}$ \\
\hline PI & 123 & 124 & 33 & 16 & 15 & 16 & 33 & 0.28 & 3.53 & 7.37 & 0.72 \\
\hline PII & 140 & 115 & 29 & 17 & 14 & 16 & 34 & 0.25 & 3.55 & 9.02 & 0.75 \\
\hline PIII & 155 & 118 & 63 & 32 & 44 & 18 & 37 & 0.54 & 2.59 & 4.32 & 1.58 \\
\hline
\end{tabular}
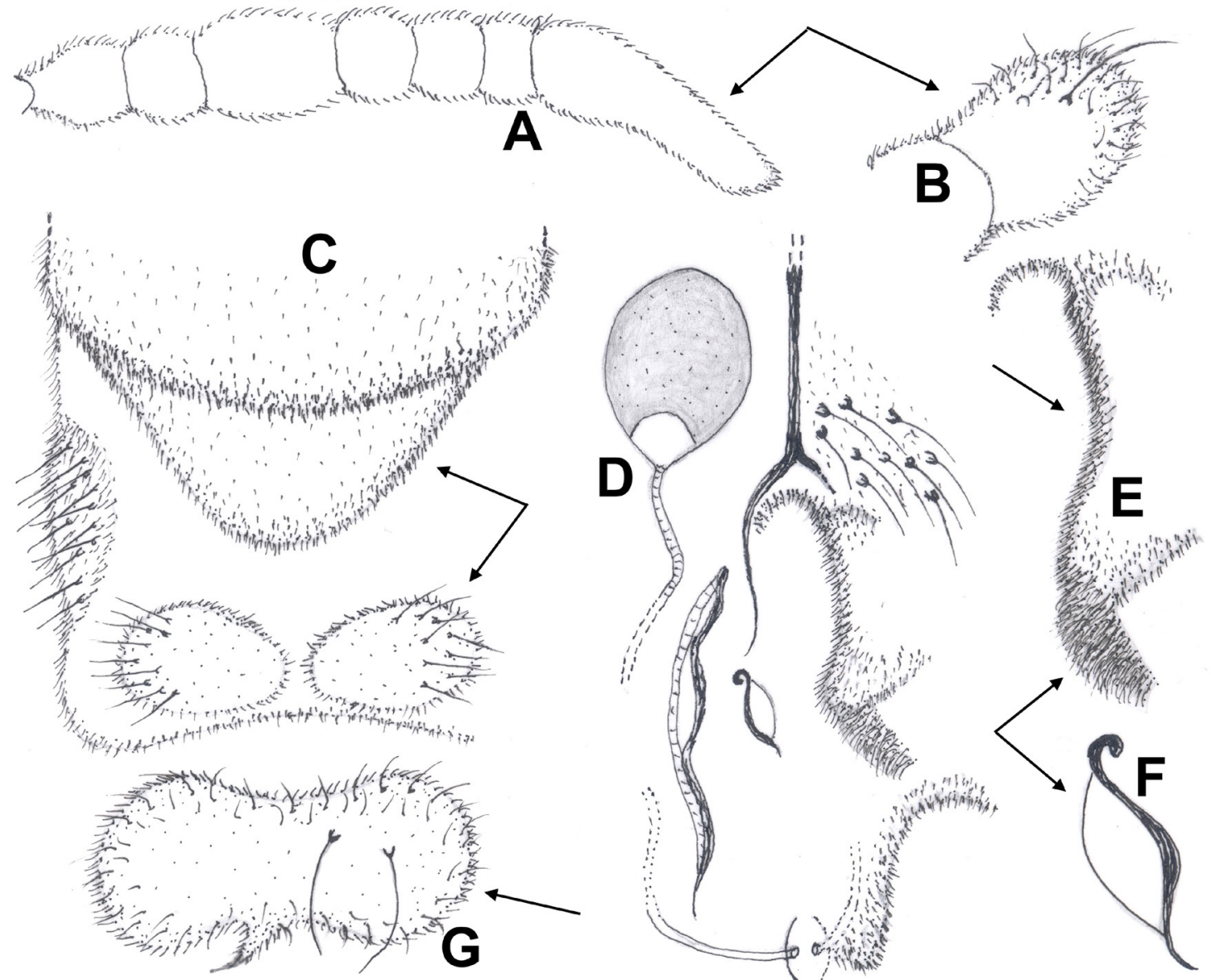

Figure 6. Female adult of Clunio ponticus. A) antenna; B) palp; C) tergite VIII, gonocoxite and tergite IX; D) gonapophysis VIII with notum and seminal capsule; E) dorsomesal lobe; F) apodeme lobe; G) cercus. The arrows indicate some distinguishing characters.

Abdomen. Anal segment (Fig. 6C, dorsal; Figs 6D and 8 , ventral) about $230 \mu \mathrm{m}$ long, $210 \mu \mathrm{m}$ maximum width at base, $110 \mu \mathrm{m}$ wide at caudal part. Genitalia (Figs 6E-F; 8). Notum about $140 \mu \mathrm{m}$ long with separate long and sinuous rami, which are almost connected to the sternal axial apodeme. Sternite VIII with 20-22 setae (10-11 on each side of the notum). Gonapophysis VIII (Figs 6D-F, 8). Dorsomesal lobe (Figs 6D-E, 8) concave medially and projecting in both proximal and apical parts; ventrolateral lobe projecting outwards, broader basally and slightly narrowing distally; apodeme lobe (Fig. 6D, right; Fig. 6F, left) distinctly swollen in its median part and thicker distally. Seminal capsules about $60 \mu \mathrm{m}$ long, $30 \mu \mathrm{m}$ maximum width, sub-oval, well-sclerotized except for its basal part. Spermathecal ducts with loops and separate openings. Tergite IX (Figs 6C, 8) egg-shaped, distinctly divided, with 18-20 setae (9-10 on each side). Gonocoxite (Figs 6C, 8) bearing 11-12 setae, weakly prominent, well-developed and widely extended vertically along the lateral margin. Cercus (Figs 6G, 8) bean-shaped with sub-equal parts, bearing 2 long dorsal setae located on 1 side.

\section{Pupal exuviae}

( $\mathrm{n}=3: 1$ male exuviae and 2 female pharate adults)

(Male pupal exuviae, Figs 9 A-E)

Exuvial length $2 \mathrm{~mm}$. Colourless. Frontal apotome 


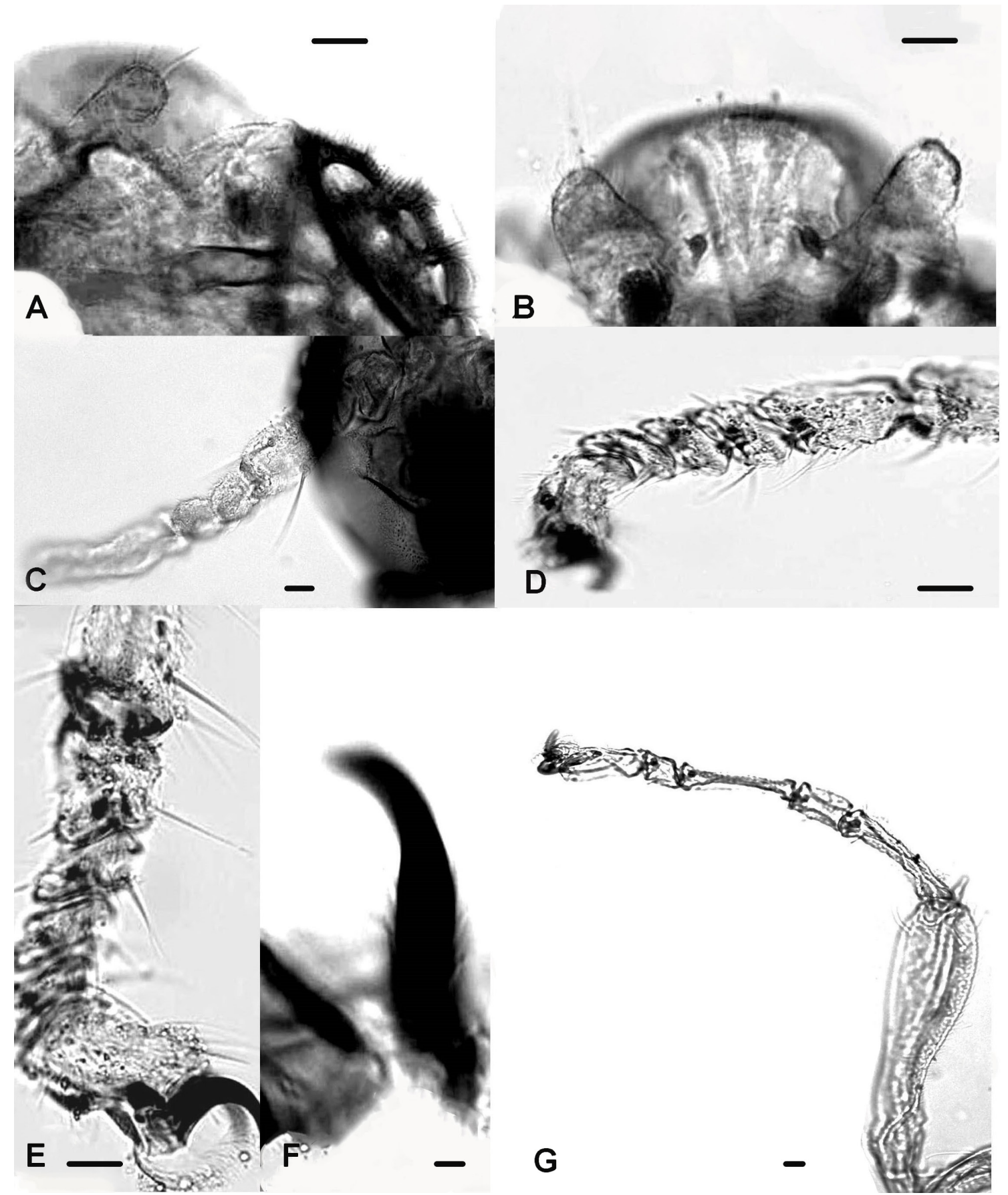

Figure 7. Female adult of Clunio ponticus. A-B) head, frontal area and palp; C) antenna, segments 4-6 and last flagellomere; D) tarsomeres of fore leg; E) tarsomeres of mid leg; F) tibial spur of hind leg; G) tarsomeres of hind leg. Scale bar $=10 \mu \mathrm{m}$.

rectangular, the free apex truncate. Thorax smooth apart from a small patch of tubercles by suture a little behind middle (Fig. 9C). 4 dorsocentral setae about $50 \mu \mathrm{m}$ long; setae 1, 2 separated by 25 $\mu \mathrm{m}, 2,3$ by $35 \mu \mathrm{m}$ and 3, 4 by $50 \mu \mathrm{m}$ (in general, setae on Clunio exuviae are very small; other than the dorsocentrals, neither frontal setae nor abdominal setae have been detected in these specimens). Wing sheath $200 \mu \mathrm{m}$ long, without nose or pearl row.
Abdominal tergites I-VII (Figs 9A-B) with a continuous anterior transverse band of colourless points; III-VII with a posterior transverse row of small hooks extending the width of the tergite. Sternites unarmed except VIII which has a posterior transverse band of minute points, restricted to the middle half in the male (Fig. 9A), but extending to the lateral margins in the female (Fig. 9D). Anal tergite without lobes, truncate apically and bearing at the postero-lateral corners two strong spines 


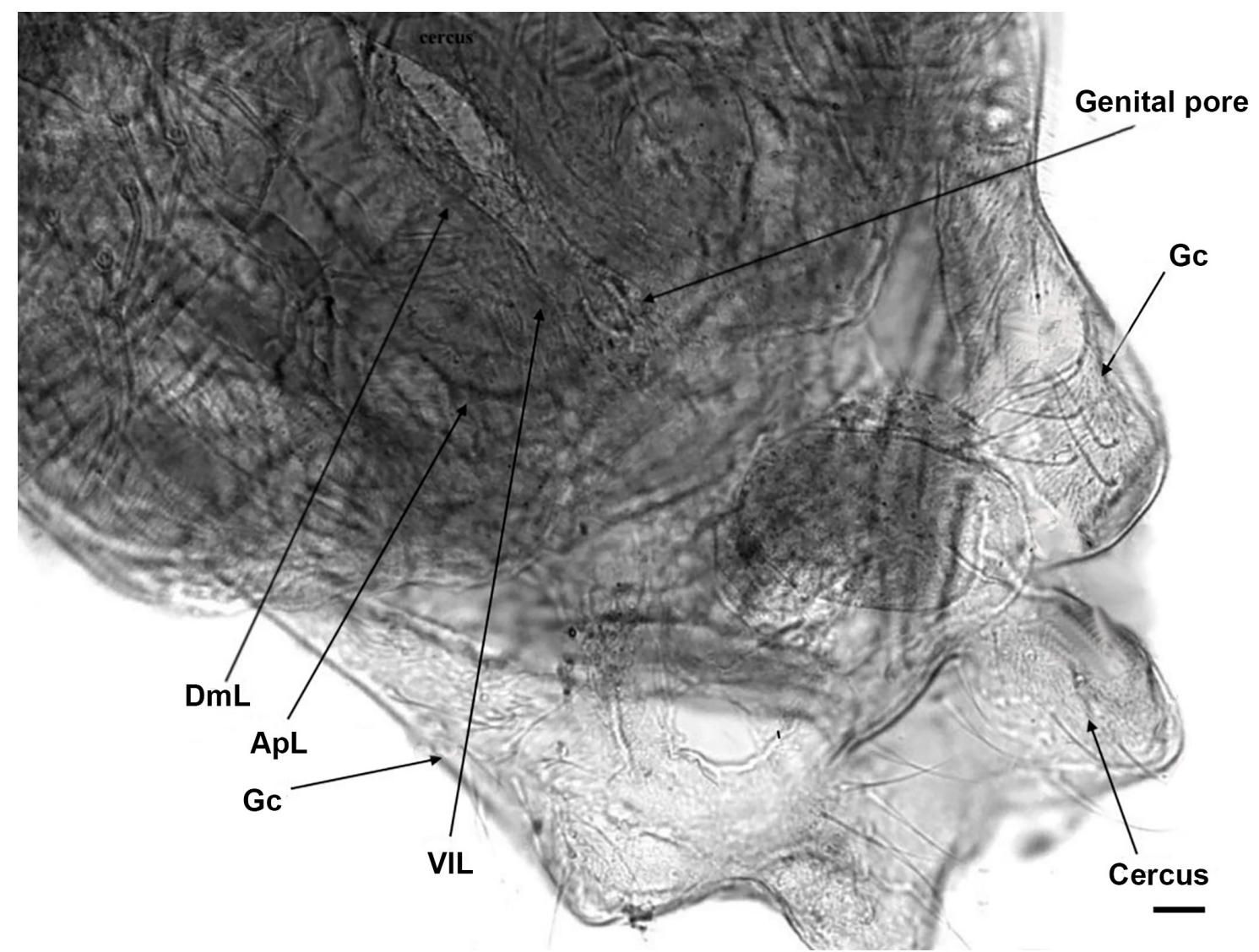

Figure 8. Female adult of Clunio ponticus. Genitalia in ventral view including gonapophysis VIII: sternite VIII, dorsomesal lobe $(\mathrm{DmL})$, apodeme lobe $(\mathrm{ApL})$, ventrolateral lobe $(\mathrm{VlL})$, genital pore, gonocoxite $(\mathrm{Gc})$ and cercus. Scale bar $=10 \mu \mathrm{m}$.

(Figs 9D-E). Female genital sheaths are restricted to a circular patch beneath the anal segment (Fig. 9D), whereas those of the male are massive, far exceeding the anal segment both laterally and posteriorly, parallel-sided for the anterior half, thence narrowed inwards to a papillate point (Fig. 9E).

\section{Fourth instar larva}

$(\mathrm{n}=7$; Figures 10-12)

Small sized species. TL about $6 \mathrm{~mm}$ long. General colouration yellowish green; head dark brown; mentum with dark brown teeth; frontal apotome dark brown, mandible with contrasting brown to pale teeth.

Head. Clypeus, frontal apotome with setae I-IV and labrum as in figures 10 and 12A. Clypeus trapezoidal with wide posterior margin, dense granulation present on both sides; setae 1 and 2 plumose, occasionally with branches; setae 3 and 4 simple; setae S1 located close to the anterior margin, setae $\mathrm{S} 2$ inserted medio-laterally. Frontal apotome (Figs 10, 12A) ellipsoidal except in its basal part; setae S3-S5 located near the lateral margin: S3 close to the anterior margin, S4 antero-medially, S5 on me- dian area. Mandible (Figs 10, 11A) with 5 teeth; apical one 100-110 $\mu \mathrm{m}$ long and 34-46 $\mu \mathrm{m}$ maximum width. Mandible subdentalis almost triangular and thin, with uneven sides, reaching the last (posterior) tooth; seta interna consists of 5 strong and conspicuous branches. Mentum (Fig. 11B); median tooth, smooth, widely domed and rounded, the four remaining lateral teeth are rounded apically and progressively decreasing in size from 1 to 4 ; in some individuals the number of lateral teeth is different from both sides. Ventromental plates poorly developed; seta submenti $42 \mu \mathrm{m}$ long, welldeveloped and not branched; distance between setae submenti is recorded in Table 3. Antenna (Fig. 11C) 5-segmented, length of segments (in $\mu \mathrm{m}$ ) as in Table 3; segment 1 with ring organ located at mid length of segment; segment 1 with a blade long, reaching apex of $4^{\text {th }}$ segment and divided in two parts; segment 2 with thin style reaching end of segment 4; segments 3 and 4 sub-equal; Lauterborn organ weak. Premandible (Fig. 11D) bare, with a blunt tooth and inner blunt tooth, toothed proximally and blunt medially. Pecten epipharyngis (Fig. 12A) consists of two fused structures at base and bearing lanceolate setae on both sides. 

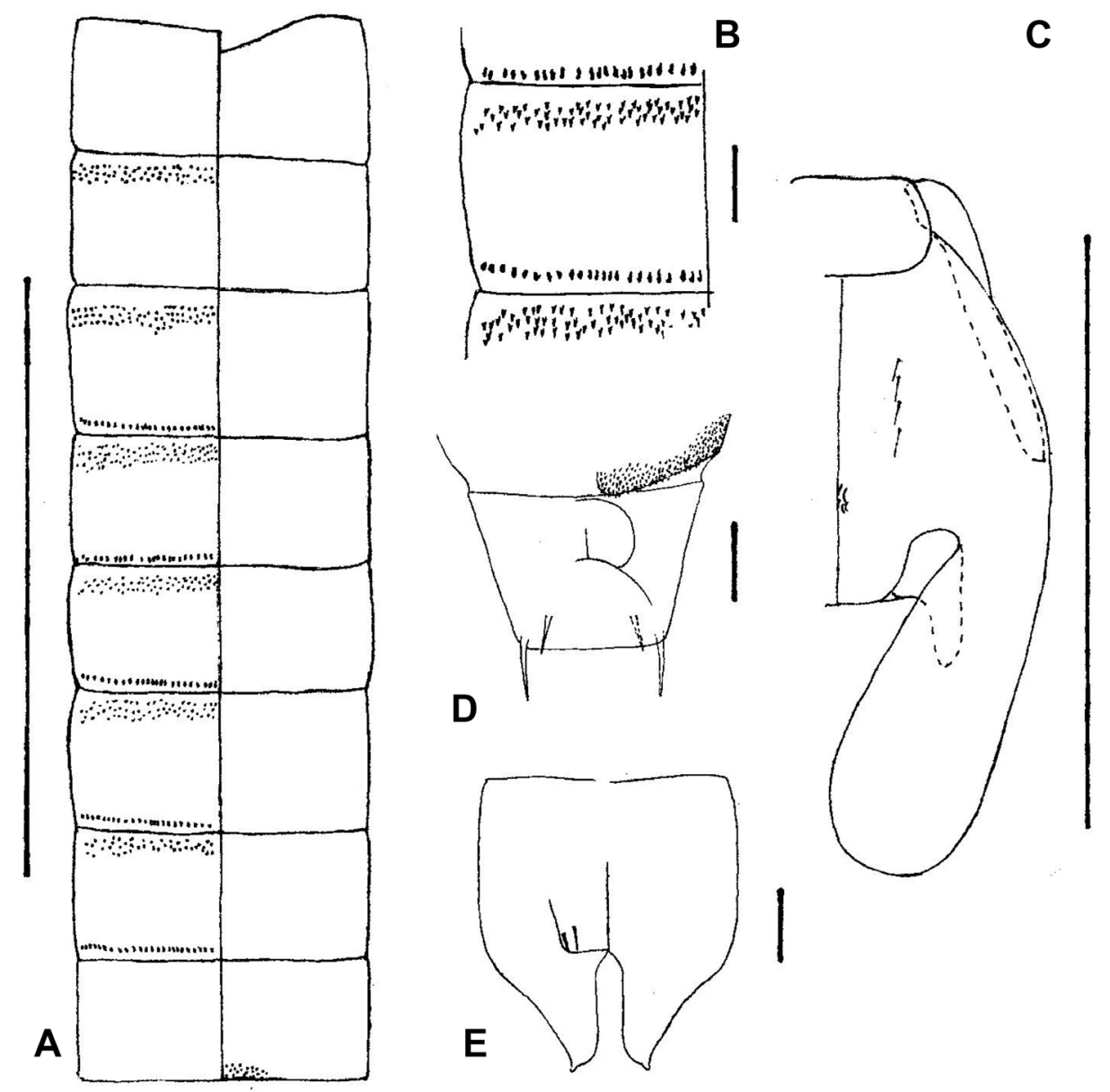

Figure 9. Pupal exuviae of Clunio ponticus. A) Abdominal segments I-VIII of male exuviae (dorsal left, ventral right); B) tergites IV (posterior) to VI (anterior); C) female segment VIII (posterior) and anal segment (left dorsal, right ventral); D) male anal segment (dorsal left, ventral right); E) frontal apotome and thorax. Scale bars: $A=1 \mathrm{~mm}$; $\mathrm{B}-\mathrm{D}=100$ $\mu \mathrm{m} ; \mathrm{E}=500 \mu \mathrm{m}$.

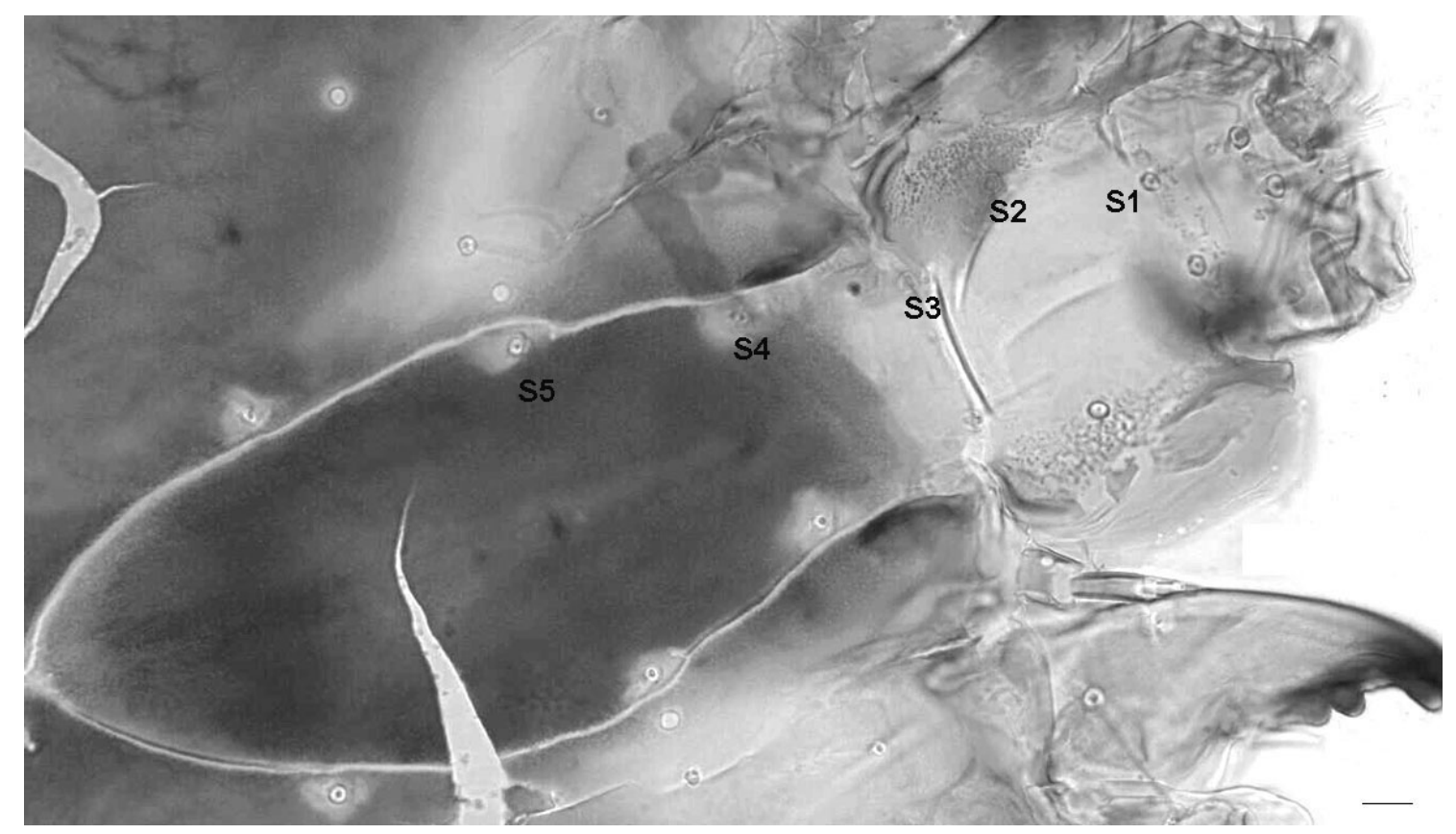

Figure 10. Larva of Clunio ponticus. Clypeus and frontal apotome with setae S1 to S5. Scale bar $=10 \mu \mathrm{m}$. 
Maxilla (Fig. 12B) with well-developed maxillary palp, bearing 1 single seta, located laterally; lacinia with several simple maxillary chaetae. Posterior parapods (Fig. 12C) about $90 \mu \mathrm{m}$ long, anal setae (as) about $65 \mu \mathrm{m}$ long, supra-anal setae, (sa) 130$135 \mu \mathrm{m}$ long; ventral tubules absent.

Table 3. Measurements in the larva of Clunio ponticus (in $\mu \mathrm{m}$ ). Antennal segments 1-2; width of median tooth of mentum; distance between mental setae; distance from antennal base to ring organ of antennal segment 1.

\begin{tabular}{cccccc}
\hline Larva & Ant. segment 1 & Ant. segment 2 & Mentum tooth & Mental setae & $\begin{array}{c}\text { Base to ring } \\
\text { organ }\end{array}$ \\
\hline 1 & 9 & 16 & 20 & 59.45 & 5 \\
2 & 9 & 16 & 24.6 & 49.2 & 5.3 \\
3 & 9 & 16 & 20 & 47.8 & 5 \\
4 & 9 & 14.7 & 24.6 & 44.9 & 5 \\
\hline
\end{tabular}
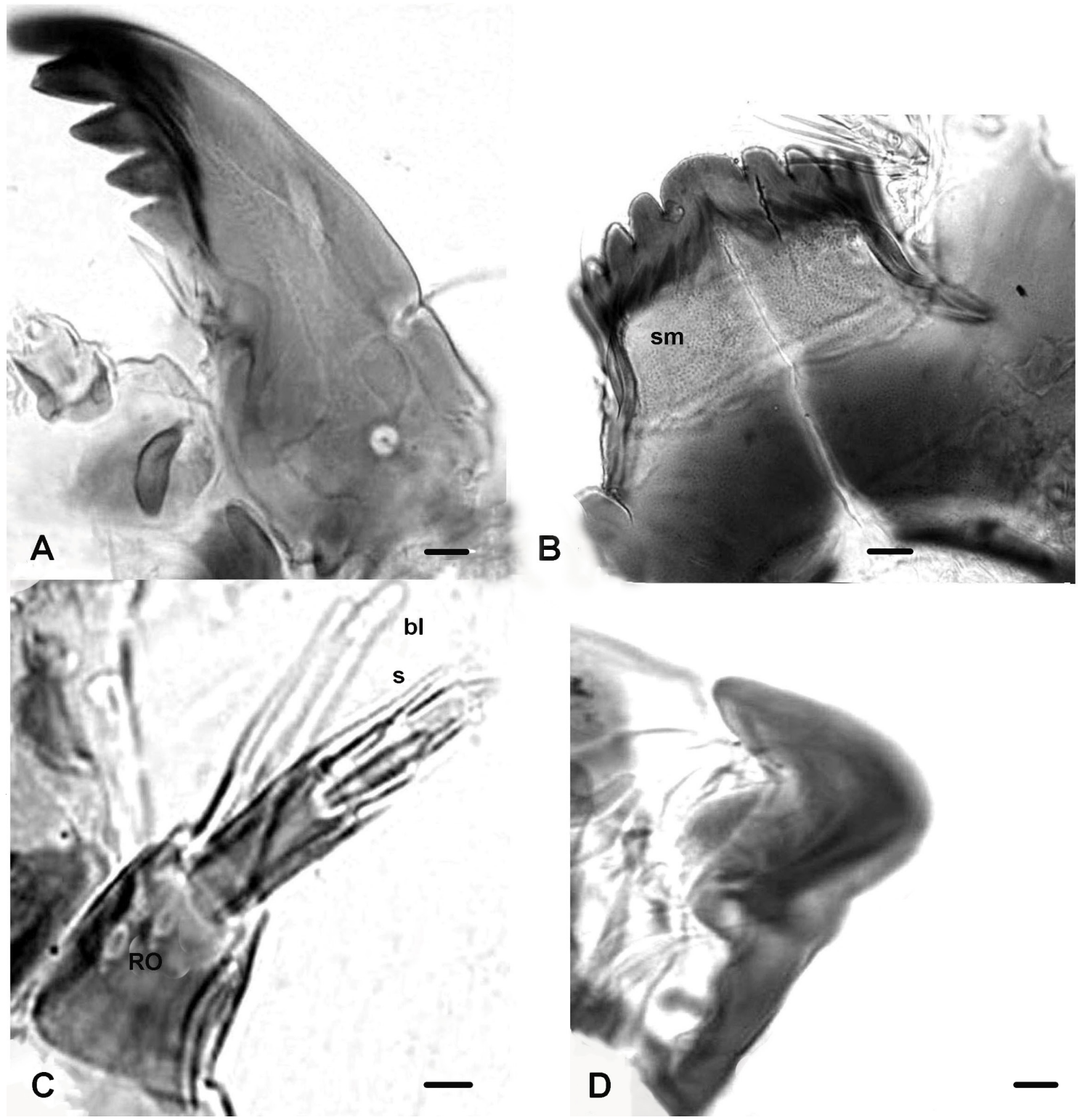

Figure 11. Larva of Clunio ponticus. A) mandible; B) mentum with median and lateral teeth; C) antenna, blade (bl), style (s); D) premandible. Scale bar $=10 \mu \mathrm{m}$. 


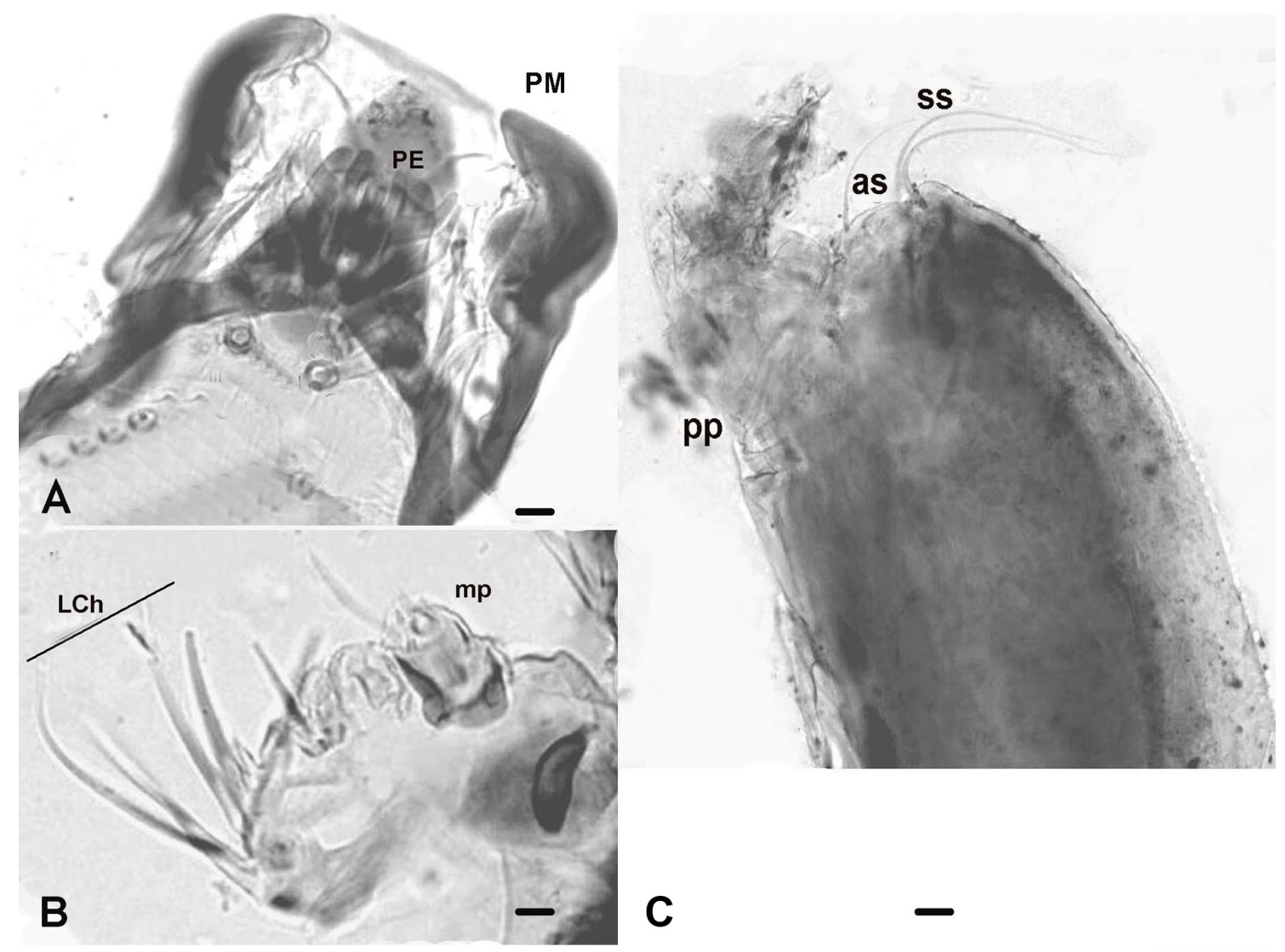

Figure 12. Larva of Clunio ponticus: A) premandible (PM), clypeus and frontal apotome, pecten epipharyngis (PE); B) maxilla with maxillary palp (mp) and lacinial chaetae (LCh); C) caudal part with posterior parapods (pp) and anal setae (as, ss). Scale bar $=10 \mu \mathrm{m}$.

\section{Differential diagnosis}

C. ponticus is easily separable from other known European Clunio species by the following morphological characters:

Male adult:

Frontal area of head with a straight anterior margin (Figs 1A, 2A), is projecting in both C. marinus (Moubayed-Breil 2019, figs 1a-b) and C. boudouresquei (Moubayed-Breil \& Dominici 2019, figs $1 \mathrm{c}-\mathrm{d})$.

Segment 2 of antenna (Figs 1B, 2A-B) globular and swollen proximally and distally, are differently shaped in C. boudouresquei (Moubayed-Breil \& Dominici 2019, fig. 1e).

Palpomere 2 sub-circular and similarly shaped (Figs 1D; 2D-E), differently shaped in C. boudouresquei (Moubayed-Breil \& Dominici 2019, Figs 1g-h) and C. marinus (Strenzke 1960, fig. 1; Moubayed-Breil 2019, fig. 1n).

Ridge of tergite VIII (Fig. 1E) broad drop-shaped, narrower in C. boudouresquei (Moubayed-Breil \& Dominici 2019) and cylindrical to inverted conical in C. marinus (Strenzke 1960, figs 12-13).
Caudal apodeme composed of 3 long claws (Figs $1 \mathrm{H}-\mathrm{I})$, bearing brush and differently shaped claws in both $C$. boudouresquei and C. mediterraneus (Moubayed-Breil \& Dominici 2019, figs 2b, 2e).

Megaseta absent on gonostylus (Figs 1J, 4C-D, 5A-D), present in C. boudouresquei (MoubayedBreil \& Dominici 2019, fig. 2c).

Apex of gonostylus with several unequal tubercles (Figs 1K-L), consisting of only a single finger-like tubercle in both $C$. boudouresquei and C. mediterraneus (Moubayed-Breil \& Dominici 2019, figs $2 b-c, 2 f)$.

Female adult:

Frontal area straight (Figs 7A-B), orally projecting in C. marinus; palpomere 2 sub-circular (Figs 7A-B), sub-rectangular in C. marinus (MoubayedBreil \& Dominici 2019, fig. 2n).

Segment 3 of antenna nearly globular (Figs 6A, 7C), elongated and parallel-sided in C. marinus (Strenzke 1960, fig. 15).

Proximal and posterior parts of dorsomesal lobe not projecting (Figs 6D-E), prominent in C. boudouresquei (Moubayed-Breil \& Dominici 2019, 
figs b, d); cercus bi-lobed medially (Fig. 6G), differently figured in C. marinus and C. boudouresquei (Strenzke 1960, fig. 19; Moubayed-Breil \& Dominici 2019, fig. 4b).

Pupal exuviae:

Anterior transverse band of points on tergites IIVII complete on all tergites (Figs 9A-B), broken medially on tergite II in C. boudouresquei (Moubayed-Breil \& Dominici 2019, fig. 5c).

Posterior transverse band of points absent on tergites, present on tergites II-VII or III-VII in $C$. boudouresquei, C. mediterraneus and C. marinus.

Transverse row of hooks absent on sternites (Fig. 9A), present on sternites IV-VII in C. marinus (Coffman et al 1986, fig. 9. 11c), V-VII in C. boudouresquei (Moubayed-Breil \& Dominici 2019, Fig. 5a) and V-VI C. mediterraneus (MoubayedBreil \& Dominici 2019, fig. 5b).

Larva:

Blade of antenna reaching apex of segment 4 (Fig. 11C), only reaching proximal half in $C$. marinus (Strenzke 1960, fig. 25) and C. sp. 1 (Abdelsalam 2017, fig. 5), reaching segment 5 in C. mediterraneus (Tasdemir, 2010, fig. 3).

Median tooth of mentum broadly domed and smooth (Fig. 11B), triangularly rounded apically in C. marinus (Strenzke 1960, fig. 31), semi-circular in C. mediterraneus (Tasdemir, 2010, fig. 4) and sub-trapezoidal in C. sp. 1 (Abdelsalam 2017, fig. 5).

DNA sequencing of species-specific genetic markers will be performed later to see how genetically divergent $C$. ponticus is compared to related species of the genus Clunio.

\section{Ecology and geographical distribution}

Larval and pupal stages of $C$. ponticus are exclusively confined to the intertidal rocky shores of the Black Sea at Varna, St. Konstantin and the Helena Resort coastline (Eastern Bulgaria, Figs 13-14), where a dense population of marine algae (Cladophora spp.) occurs.

While the biological cycle (reproduction and emergence) is synchronized with the lunar cycle (new and full moon) for C. boudouresquei, C. marinus and C. mediterraneus (Neumann 1976, Neumann et al. 1997, Kaiser \& Heckel 2012, MoubayedBreil \& Dominici 2019), that of C. ponticus is independent of the lunar periodicity but closely related to the typology of the marine intertidal zone, which consists of mostly submerged habitat along the coastline of the Black Sea. Emergence of $C$. ponticus is observed early in the morning in slight tide and has no semi-lunar periodicity.

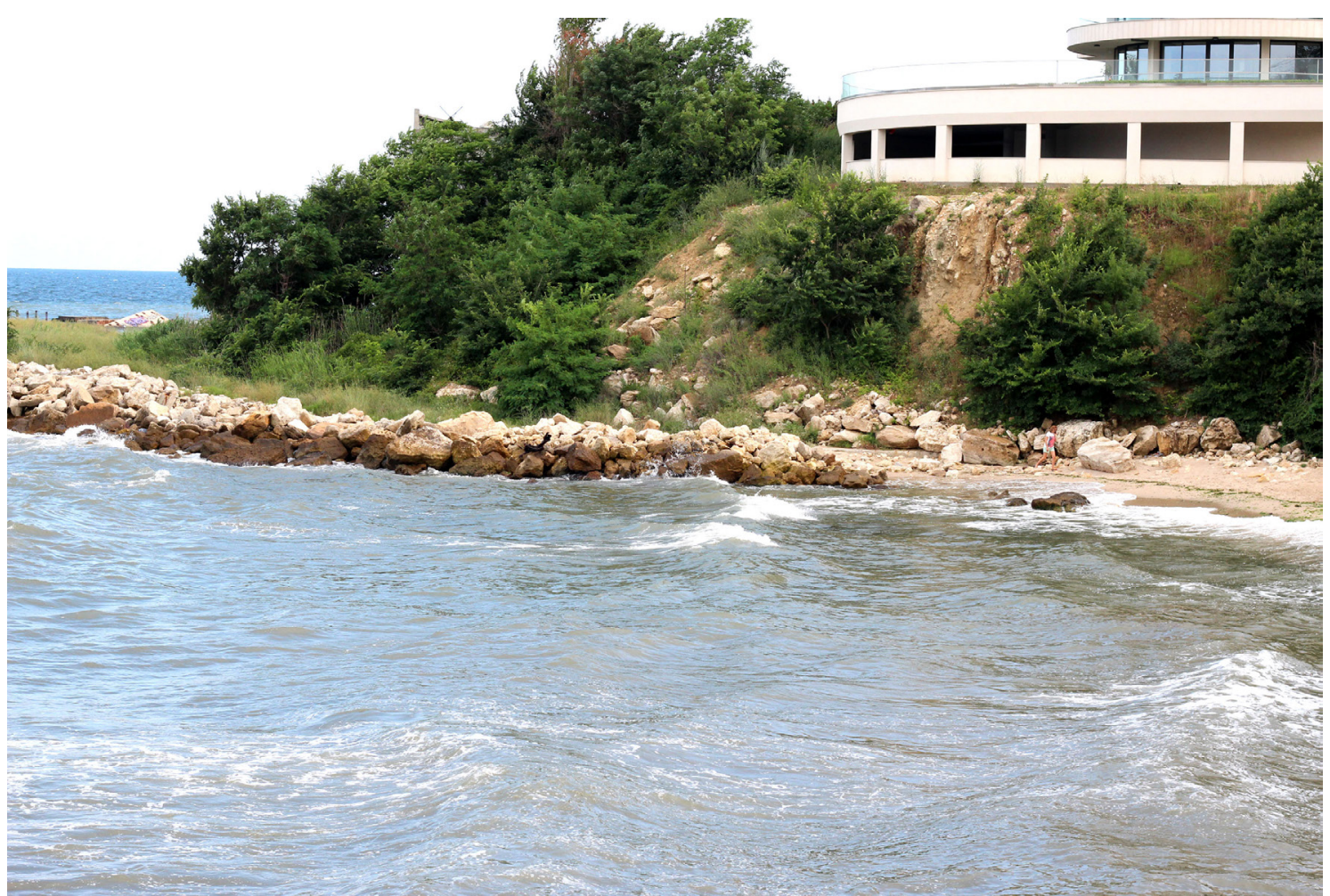

Figure 13. Type locality at Varna seashores, St. Konstantin and Helena Resort (Black Sea, eastern Bulgaria), where the topotypes of C. ponticus were collected. Photo P. Michailova, 26.VI.2019. 


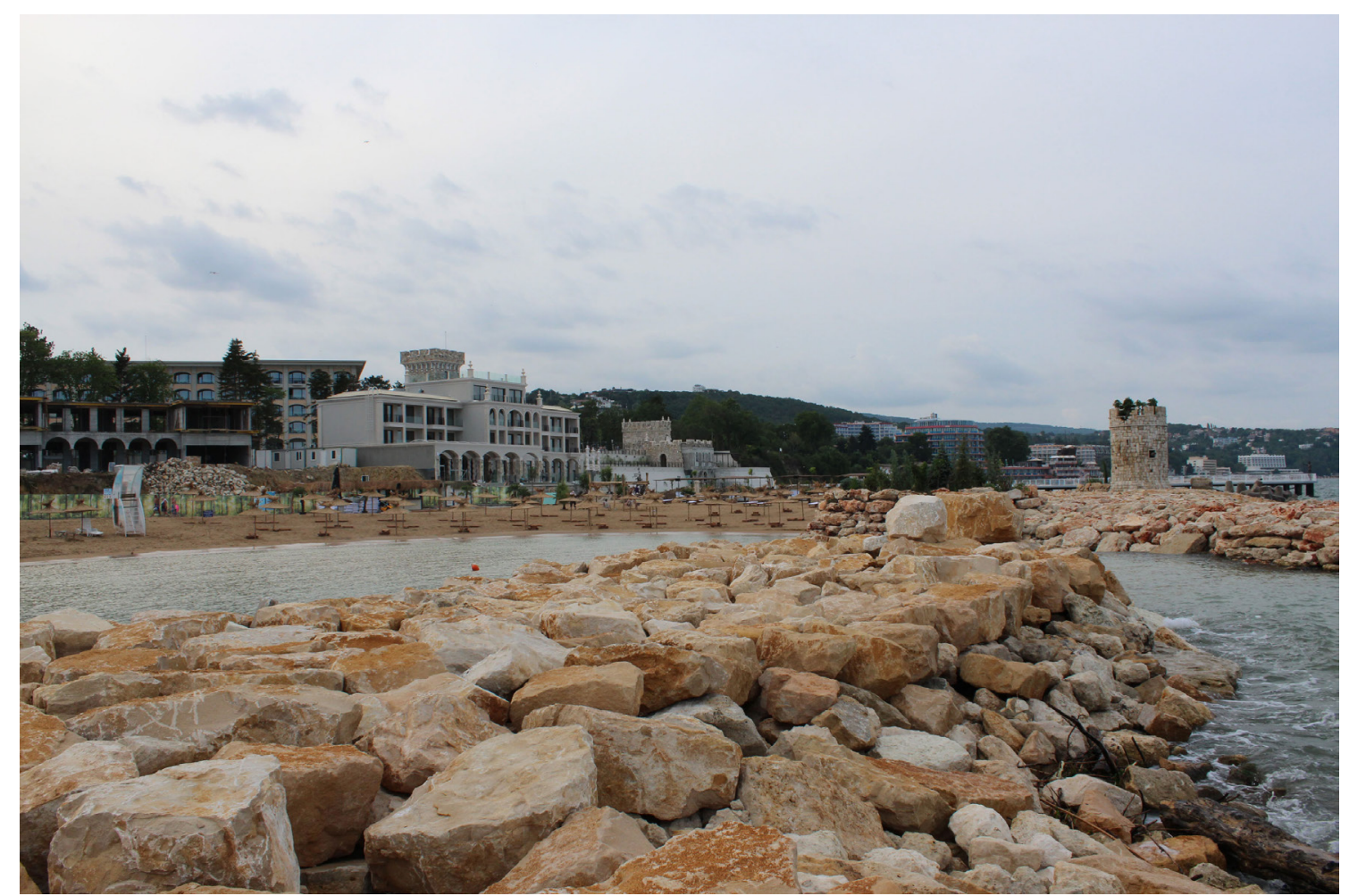

Figure 14. Varna coast, St. Konstantin and Helena Resort (Black Sea, eastern Bulgaria): modified marine habitats by recent constructions at the neareby seashores. Photo P. Michailova, 26.VI.2019.

Larvae live in general among the filiform marine algae but sometimes inhabit tubes built with sandy to muddy sediment among stones on the seabed. Copulation takes place mainly on the water surface during low tide: the female dragged along by the male in end-to-end position. Male adults emerge from May to early July slightly earlier than the females: they occur early in the morning between 5 and $7 \mathrm{am}$.

The littoral and mid-littoral marine zones of the type locality where new material of $C$. ponticus was recently collected have been much degraded over the last four decades by various perturbations related to human activities and tourism (Fig. 14).

\section{Acknowledgements}

The authors are grateful to their colleague Dr. Torbjørn Ekrem (NTNU, Trondheim, Norway) and an anonomous reviewer for constructive and valuable suggestions, which improved the manuscript.

\section{References}

Abdelsalam, K.M. 2017. The genus Clunio Haliday, 1855 from Egypt (Hurghada, Red Sea) with a description of the larva of Clunio sp.1 (Diptera, Chironomidae, Orthocladiinae). Polish Journal of Entomology, 86: 39-47. DOI: https://doi: 0.1515/pjen-2017-0003

Andersen, T., Sæther, O.A., Cranston, P.S. and
Epler, J.H. 2013. The larvae of Orthocladiinae (Diptera: Chironomidae) of the Holarctic Region - keys and diagnoses. - Insect Systematics \& Evolution, Supplement 66: 189-386.

Ashe, P. and O'Connor, J.P. 2012. A World Catalogue of Chironomidae (Diptera). Part 2. Orthocladiinae. Irish Biogeographical Society \& National Museum of Ireland, Dublin. 1-968. https://doi.org/10.5324/fn.v31i0.1366

Coffman, W.P., Cranston, P.S., Oliver, D.R. and Scether, O.A. 1986. The pupae of Orthocladiinae (Diptera: Chironomidae) of the Holarctic Region - keys and diagnoses. - Entomologica Scandinavica, Supplement 28: 147-296.

Cranston, P.S., Oliver, D.R. and Scether, O.A. 1989. The adult males of Orthocladiinae (Diptera: Chironomidae) of the Holarctic Region - keys and diagnoses. - Entomologica Scandinavica, Supplement 34: 164-352.

Heimbach, F. 1978. Sympatric species, Clunio marinus Hal. and C. balticus n. sp. (Dipt., Chironomidae), isolated by differences in diel emergence time. Oecologia (Berl.) 32: 195202. https://doi.org/10.1007/BF00366071

Kaiser, T.S., Heckel, D.G. 2012. Genetic architecture of local adaptation in lunar and diurnal emergence times of the marine midge Clunio marinus (Chironomidae, Diptera). PLoS ONE 
(2): e32092: 1-14. https://doi.org/10.1371/ journal.pone.0032092

Langton, P.H. 1991. A key to pupal exuviae of the West Palaearctic Chironomidae. Privately published. Huntingdon, England, 386 pp.

Langton, P.H. and Pinder, L.C.V. 2007. Keys to the adult males of Chironomidae of Britain and Ireland. Volume 1 (Pp: 1-239) and volume 2 (Pp. 1-68). Freshwater Biological Association, Scientific Publication, $\mathrm{n}^{\circ} 64$.

Michailova, P. 1980a. Comparative external morphological and karyological characteristics of European species of genus Clunio Haliday, 1855 (Diptera, Chironomidae). In: Murray D.A. (ed.) Chironomidae. Pergamon Press, Oxford: 9-15. https://doi.org/10.1016/B978-008-025889-8.50007-6

Michailova, P. 1980b. A review of the European species of genus Clunio Haliday, 1855 (Diptera, Chironomidae). - Zoologischer Anzeiger 205(5/6): 417-432.

Moubayed-Breil, J. and Ashe, P. 2012. An updated checklist of the Chironomidae of Corsica with an outline of their altitudinal and geographical distribution (Diptera). - Ephemera 13(1): 1339.

Moubayed-Breil, J. and Ashe, P. 2016. New records and additions to the database on the geographical distribution of some threatened chironomid species from continental France [Diptera, Chironomidae]. - Ephemera 16(2): 121-136.

Moubayed-Breil, J., Verlaque, M., Dominici, J.M. and Bianconi, C.H. 2013. Estuarine zones of Corsica: Faunal, ecological and biogeographical data. - Travaux de l'Institut Scientifique, Rabat, Série Zoologie, 49: 43-58.

Neumann, D. 1976. Adaptation of chironomids to intertidal environments. - Annual Revue of Entomology 21: 387-414. https://doi.org/10.1146/ annurev.en.21.010176.002131
Neumann, D., Kaminsky, R. and Heimbach, F. 1997. Timing of eclosion in marine insects on Mediterranean shores-studies on Clunio mediterraneus, C. ponticus and Thalassomyia frauenfeldi (Diptera: Chironomidae). - Marine Biology 129(3): 513-521. https://doi.org/10.1007/ s002270050192

Olander, R. and Palmén, E. 1968. Taxonomy, ecology and behaviour of the northern Baltic $\mathrm{Cl}$ unio marinus Halid. (Dipt., Chironomidae). Annales Zoologici Fennici, 5: 97-110.

Sæther, O.A. 1977. Female genitalia in Chironomidae and other Nematocera: morphology, phylogenies, keys. - Bulletin of the Fisheries Research Board of Canada 197: 1-209.

Sæther, O.A. 1980. Glossary of chironomid morphology terminology (Diptera: Chironomidae). - Entomologica Scandinavica, Supplement 14: $1-51$.

Sæther, O.A., Ashe, P. and Murray, D.A. 2000. Family Chironomidae. In: Papp, L. and Darvas, B. (Eds.) Contributions to a Manual of Palaearctic Diptera (with special reference to flies of economic importance). Science Herald, Budapest, 4 (A6): 113-334.

Sæther, O.A. and Spies, M. 2013. Fauna Europaea: Chironomidae. In P. Beuk \& T. Pape (eds): Fauna Europaea: Diptera Nematocera. Fauna Europaea version 2.6. Internet database at http://www.faunaeur.org [accessed February 2015].

Strenzke, K. 1960. Metamorphose und verwadtschaftsbeziehungen der gattung Clunio Hal. (Dipt.). Terrestrische Chironomidae XXIV. Annales Zoologigi Societatis Zoologigae Botanicae Fennicae 'Vasamo', 22(4): 1-30.

Tasdemir, A. 2010. Clunio Haliday, 1855: A new chironomid genus for Turkey (Diptera, Chironomidae). - Journal of the Entomological Research Society 12(3): 39-43. 